\title{
Review
}

\section{Exercise Hypertension}

\author{
Martin G. Schultz James E. Sharman \\ Menzies Research Institute Tasmania, University of Tasmania, Hobart, Tas., Australia
}

\section{Key Words}

Resting blood pressure - Exercise hypertension - Hypertensive response to exercise · Lifestyle interventions - Blood pressure control

\begin{abstract}
Irrespective of apparent 'normal' resting blood pressure (BP), some individuals may experience an excessive elevation in BP with exercise (i.e. systolic BP $\geq 210 \mathrm{~mm} \mathrm{Hg}$ in men or $\geq 190$ $\mathrm{mm} \mathrm{Hg}$ in women or diastolic BP $\geq 110 \mathrm{~mm} \mathrm{Hg}$ in men or women), a condition termed exercise hypertension or a 'hypertensive response to exercise' (HRE). An HRE is a relatively common condition that is identified during standard exercise stress testing; however, due to a lack of information with respect to the clinical ramifications of an HRE, little value is usually placed on such a finding. In this review, we discuss both the clinical importance and underlying physiological contributors of exercise hypertension. Indeed, an HRE is associated with an increased propensity for target organ damage and also predicts the future development of hypertension, cardiovascular events and mortality, independent of resting BP. Moreover, recent work has highlighted that some of the elevated cardiovascular risks associated with an HRE may be related to high-normal resting BP (pre-hypertension) or ambulatory 'masked' hypertension and that an HRE may be an early warning signal of abnormal BP control that is otherwise undetected with clinic BP. Whilst an HRE may be amenable to treatment via pharmacological and lifestyle interventions, the exact physiological mechanism of an HRE remains elusive, but it is likely a manifestation of multiple factors including large artery stiffness, increased peripheral resistance, neural circulatory control and metabolic irregularity. Future research focus may be directed towards determining threshold values to denote the increased risk associated with an HRE and further resolution of the underlying physiological factors involved in the pathogenesis of an HRE.


Schultz and Sharman: Exercise Hypertension

\section{Introduction}

Exercise stress testing is routinely performed to assess cardiovascular (CV) risk and reveal CV abnormalities which are not always identifiable at rest (i.e. coronary artery disease, arrhythmias). Worldwide, many millions of exercise stress tests are conducted annually, and in Australia alone, there are in excess of 400,000 tests undertaken each year [1]. The measurement of brachial blood pressure (BP) is a fundamental component of an exercise stress test and should be performed prior to and at all incremental stages of a test [2]. It is generally well known that abnormally low exercise BP is a poor prognostic sign related to cardiac dysfunction and an indication for stopping an exercise test $[2,3]$. On the other hand, there is less certainty with regard to the relevance of an exaggerated or 'hypertensive response to exercise' (HRE). This is defined as apparently 'normal' resting BP (<140/90 mm Hg) but excessively high exercise BP. Despite an HRE being a relatively common condition that is often reported by the physician supervising the test, little emphasis is placed on the result owing to the lack of information with respect to the clinical ramifications of such a finding. Recent data indicate that an HRE is indeed prognostically significant and may be a marker of poor BP control, but the underlying pathophysiologicalmechanisms remain poorly understood. This review aims to summarise the available evidence regarding exercise BP and the potential clinical importance of exercise hypertension, as well as to discuss possible contributory mechanisms.

\section{Exercise BP: The 'Normal' Physiological Response}

Initiation of dynamic physical activity (such as running or cycling) increases the metabolic demands of the active musculature. The blood flow is directed away from non-active circulatory beds, and vasodilation of the arterioles supplying the active muscles will cause a reduction in systemic vascular resistance [4]. In order to supply the increased demand for oxygenated blood in the active regions, the cardiac output is boosted by an immediate increase in sympathetic activity and heart rate, as well as by an optimisation of myocardial contractility and relaxation (i.e. positive inotropy and lusitropy) and elevated venous return. The rise in the cardiac output predominates over reduced vascular resistance, and consequently there is an overall elevation of mean arterial pressure [5]. Whilst diastolic BP remains relatively unchanged (perhaps decreasing slightly), systolic BP is expected to rise in a curvilinear or step-wise manner with increasing intensity of treadmill or cycle exercise [6], theoretically reaching its peak value at maximal exercise intensity (fig. 1).

\section{Definition and Prevalence of an HRE}

There is no consensus as to a specific 'threshold' value of exercise BP that constitutes an HRE. However, there is some consistency among studies to show that exercise hypertension (defined as $\geq 90$ th percentile from age- and sex-specific normative data) [7] approximates a systolic BP of $\geq 210 \mathrm{~mm} \mathrm{Hg}$ for males and $\geq 190 \mathrm{~mm} \mathrm{Hg}$ for females and, although less commonly observed, a diastolic BP $\geq 110 \mathrm{~mm} \mathrm{Hg}$ for both males and females at any exercise workload (fig. 1) [8-11]. An HRE may occur irrespective of whether resting BP levels fall within a non-hypertensive range $(<140 / 90 \mathrm{~mm} \mathrm{Hg})$ or if antihypertensive medication is being used. Furthermore, an HRE may occur at any exercise intensity, either during exercise or in the immediate recovery period following exercise. Evidence from our own studies also suggests that a systolic BP $\geq 175 \mathrm{~mm} \mathrm{Hg}$ at light-moderate exercise workload may signify a threshold of increased risk related to an HRE at this exercise intensity (fig. 1) [12,13]. 


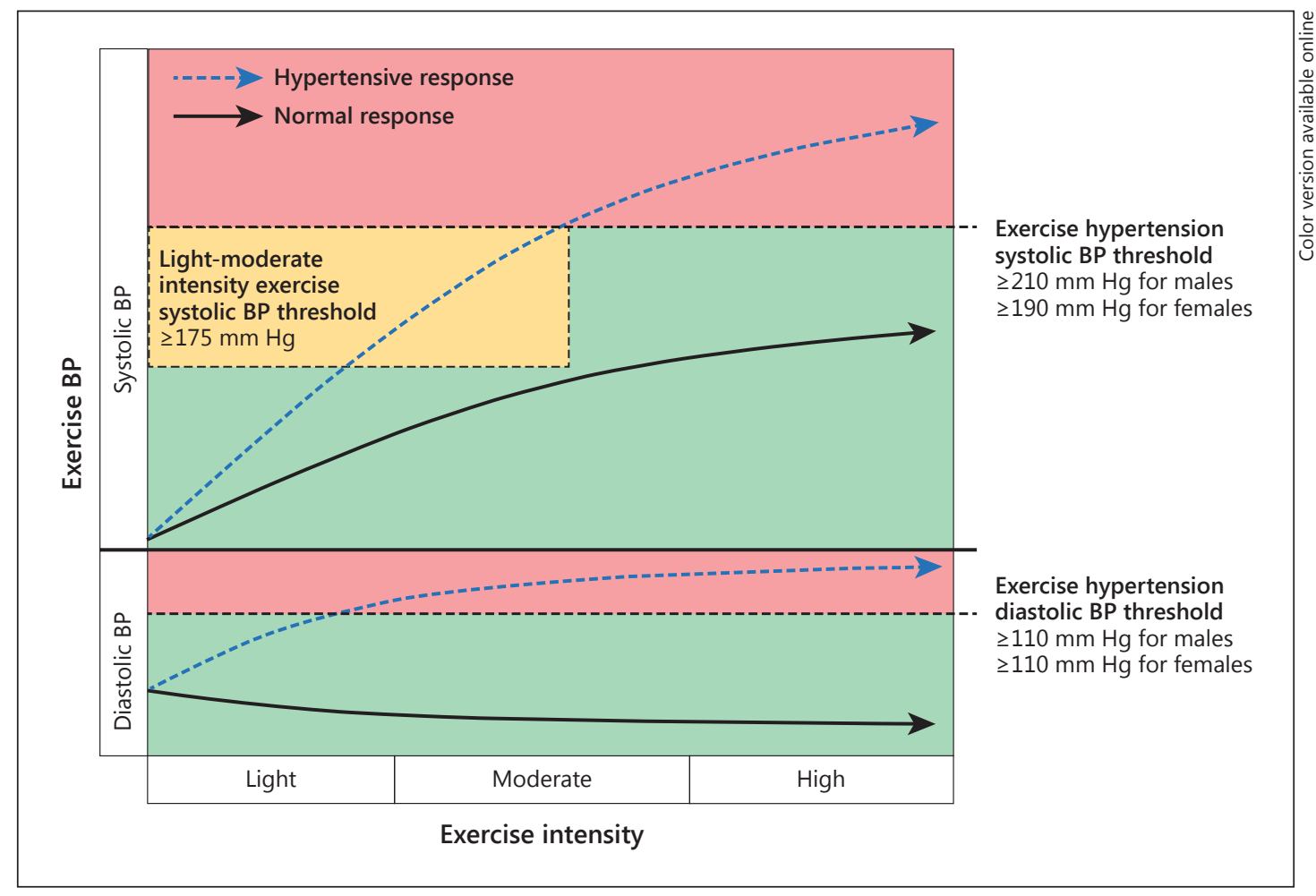

Fig. 1. Illustration depicting the normotensive and hypertensive response to dynamic physical exercise (HRE). The normotensive response (solid arrows) shows systolic BP gradually increasing in a curvilinear fashion with exercise intensity, whereas diastolic BP remains largely unchanged or slightly decreased. An HRE is depicted by broken arrows and illustrates how both systolic and diastolic BP may increase to a greater extent than a normotensive response, crossing respective BP thresholds (note that this could occur at any exercise intensity) that denote exercise hypertension (systolic BP $\geq 210 \mathrm{~mm} \mathrm{Hg}$ for males and $\geq 190 \mathrm{~mm} \mathrm{Hg}$ for females, and diastolic BP $\geq 110 \mathrm{~mm} \mathrm{Hg}$ for both males and females). Increased propensity to have $\mathrm{MH}$ (and increased CV risk) may be identified at a threshold of systolic BP $\geq 175 \mathrm{~mm} \mathrm{Hg}$ during light-moderate intensity exercise [based on Schultz et al. 12].

The prevalence of an HRE varies between studies that have used different criteria to define an HRE but is also dependent on the clinical characteristics of individual study populations. Indeed, an $18 \%$ prevalence of an HRE has been reported in a large $(n=3,741)$ normotensive cohort of young men and women [14], whereas a prevalence of $40 \%$ was found in a population of healthy middle-aged men [15]. A lower estimate from a recent systematic review placed the prevalence of an HRE across multiple apparently healthy cohorts of varying age, sex and ethnicity to be approximately 3-4\% [16]. Interestingly, several studies have reported greater prevalence of an HRE in individuals with type 2 diabetes mellitus (T2DM; e.g. $>50 \%)[14,15,17]$. Several studies have also reported that an HRE may be more likely in those with ambulatory or 'masked' hypertension (MH), with HRE prevalence ranging from 40 to $58 \%[18,19]$. Furthermore, resting BP is on average slightly higher in those with an HRE compared to individuals with normal exercise BP [20]. This means that at rest, individuals with an HRE could be classified in the 'high-normal' or pre-hypertension range as defined by the Joint National Committee (JNC-7) criteria (BP from >120/80 to 139/89 $\mathrm{mm} \mathrm{Hg}$ ) [21]. This may suggest that an HRE is indicative of an early-phase development of essential hypertension and alludes to a potential crossover in the conditions of pre-hypertension, $\mathrm{MH}$ and an 
Schultz and Sharman: Exercise Hypertension

HRE. In addition, exercise hypertension is known to be associated with older age [7,22], male sex [7], low-level fitness [20,22] and is subject to seasonal variations (higher exercise BP in winter/cold months] [23, 24].

\section{The Prognostic Significance of Exercise Hypertension}

\section{Future Development of Hypertension}

Numerous studies have examined the ability of an HRE to predict the future development of hypertension, although among this work there is wide variability in relation to study design, participant clinical characteristics and the criteria used to define an HRE [11,25-32]. Overall, there is a consistent relationship between presentation of an HRE at baseline examination when resting $\mathrm{BP}$ is $<140 / 90 \mathrm{~mm} \mathrm{Hg}$ and the future incidence of sustained hypertension (defined as resting clinic BP $\geq 140 / 90 \mathrm{~mm} \mathrm{Hg}$ ). A study of note in this area is the work of Manolio et al. [11], who investigated the relationship between an HRE during treadmill testing and 5-year incident hypertension in 3,741 normotensive subjects. After adjustment for age, sex, resting systolic BP and other CV risk factors, an HRE was associated with a 2.14-mm $\mathrm{Hg}$ increase in resting systolic BP at year $5(\mathrm{p}<0.001)$. Other large prospective cohort studies including the Framingham Heart Study [31] and the Japanese 'Osaka Health Study' [30] confirm the independent association of an HRE with the future incidence of hypertension in those with normal BP at baseline. This association may be stronger in individuals with prehypertension. Indeed, using a Cox proportional hazards survival model, Miyai et al. [29] showed that after a mean follow-up period of 5.1 years, an HRE was independently associated with the risk of developing hypertension in individuals with pre-hypertension after adjustment for traditional CV risk factors (risk ratio $=2.31,95 \% \mathrm{CI}=1.45-6.25$ ). Since pre-hypertension (irrespective of exercise BP response) is also a precursor of future sustained hypertension [33], this observation is further indirect evidence of a possible overlap between the conditions of pre-hypertension and an HRE. However, a limitation of many studies in this area is that hypertension has usually been defined on the basis of clinic BP measures alone. Therefore, in the absence of out-of-clinic BP assessment, true BP control cannot be confirmed.

\section{Relationship with Left Ventricular Structure and Function}

One of the first studies to examine the relationship between exercise BP (measured intraarterially) and target organ damage in individuals with hypertension, concluded that exercise BP may have no greater association with indexes of left ventricular (LV) hypertrophy than BP measured at rest [34]. Despite this, numerous studies (predominantly cross-sectional in design) have shown modest but significant relationships between non-invasively measured exercise BP and adverse LV structure [e.g. increased LV mass index and relative wall thickness (RWT)] in healthy individuals, as well as in those with borderline or essential hypertension, or T2DM [15, 35-41]. A very high prevalence of LV hypertrophy (67\%) was found in individuals with an HRE in the large general population cohort of men and women from the Framingham Heart Study [42]. In this study, the LV mass was $10 \%$ greater in those with an HRE when compared to those with a normal exercise BP response [42]. This is an important finding, given that LV structural alteration is a cardinal sign of target organ damage associated with hypertension and increases the propensity for developing fatal arrhythmias [43, 44]. The relationship between LV mass and an HRE was, however, weakened after adjustment for age, body mass and resting BP, suggesting a possible confounding by these factors [42]. Nonetheless, we have found that LV RWT is significantly higher $(0.41 \pm 0.09$ vs. $0.36 \pm 0.08$; $p<$ 0.05 ) and LV hypertrophy significantly more prevalent (35 vs. $16 \% ; \mathrm{p}<0.05$ ) in individuals with T2DM who exhibit an HRE when compared to those with a normal exercise BP response 


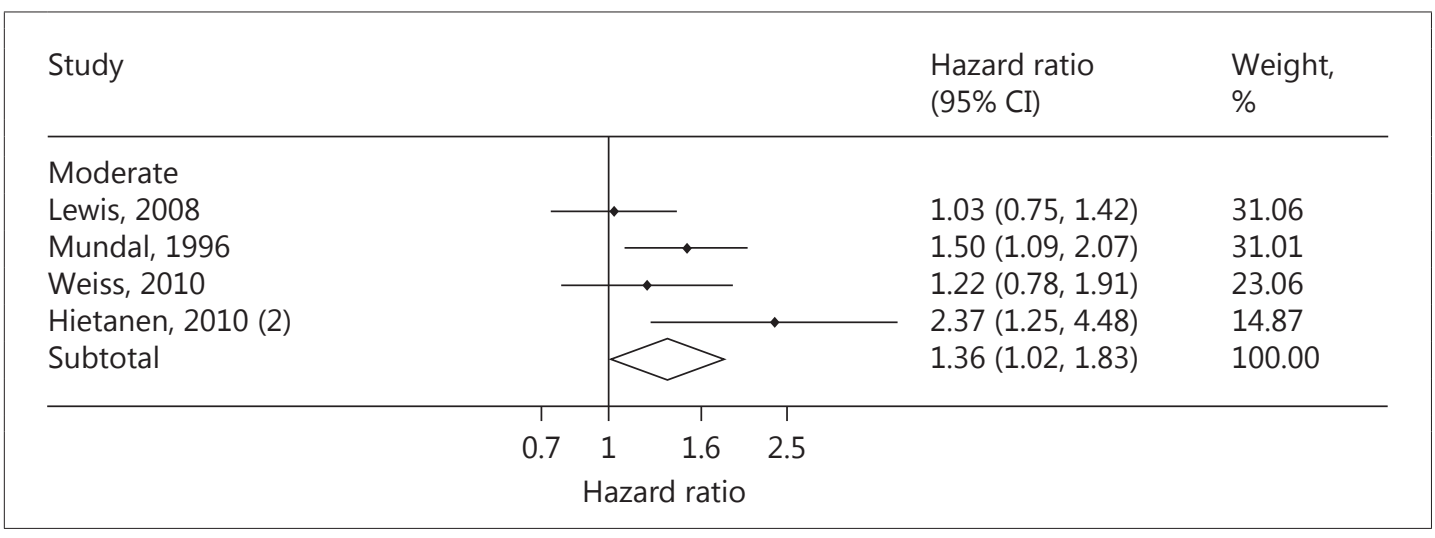

Fig. 2. Pooled HRs and 95\% CIs for an HRE at moderate exercise workload after adjustment for age, office $\mathrm{BP}$ and multiple CV risk factors ( $\mathrm{p}$ value $=0.039, \mathrm{I}^{2}=51.8 \%$ ). Modified from Schultz et al. [54] with permission from Oxford University Press.

[15]. Moreover, subtle indices of LV systolic dysfunction (impaired LV strain rate, peak systolic strain) were associated with an HRE in the study of Mottram et al. [10], which adds further weight to the idea that an HRE could be a representative sign of early-stage hypertensive heart disease.

\section{Prediction of CV Events and Mortality}

The prognostic utility of an HRE in relation to the prediction of future CV events and/or mortality has produced fairly consistent findings. The first long-term follow-up study in a large cohort of apparently healthy individuals found that an exaggerated systolic BP recorded during upright cycle ergometry predicted both $\mathrm{CV}$ and all-cause mortality, independent of resting $\mathrm{BP}$ [45]. Since then, numerous studies have confirmed that an HRE, recorded at either moderate and/or maximal exercise workloads, predicts future adverse CV events (including myocardial infarction, cerebrovascular events and development of coronary artery disease) and CV and/ or all-cause mortality [9, 46-53]. Among these studies was wide variation in the methods used to define an HRE as well as the time taken to provoke an exaggerated exercise BP response (e.g. moderate or maximal workloads, during exercise or in the recovery periods following an exercise test). Thus, the prognostic importance of an HRE was not abundantly clear.

We recently sought to clarify this in a systematic review and meta-analysis, pooling exercise and clinical outcome data from multiple studies that incorporated 12,648 healthy participants followed for a mean of 17 years [54]. Independent of resting BP and other traditional CV risk factors, we found a $36 \%$ increase in the rate of CV events and mortality in individuals with an HRE at moderate exercise intensity [hazard ratio (HR) $=1.36,95 \% \mathrm{CI}=1.02-$ 1.83; $p=0.039$; fig. 2] [54]. In addition, a 4\% increase in CV events and mortality for each 10 -mm Hg rise in moderate intensity exercise systolic BP was observed. These results suggest that only a moderate exercise workload (such as that achieved at the first or second stage of an exercise stress test), akin to the intensity experienced during everyday 'ambulatory' activities was required to elicit a prognostically significant elevation in exercise BP in healthy individuals. Indeed, when pooling studies in which an HRE was recorded at maximal exercise intensity, the association with CV events and/or mortality was no longer significant (HR = $1.49,95 \% \mathrm{CI}=0.90-2.46 ; \mathrm{p}=0.12$ ). We speculated that this finding may be related to the greater variation in maximal exercise BP due to noise and movement artefact associated with higher intensity exercise. 
Whilst the results of this meta-analysis are of potential clinical relevance for individuals who have a normal resting BP and no known CV pathology, prospective studies in individuals with underlying CV or coronary artery disease show that an HRE does not correlate with increased mortality rates [8, 55-59]. Indeed, in these 'higher-risk' patient cohorts, an HRE may be viewed as protective against adverse outcomes, possibly because this response is indicative of maintenance of myocardial function.

\section{What Determines the Increased CV Risk Associated with Exercise Hypertension?}

Whilst there is significant data to infer that an HRE is clinically important, there is little understanding as to why an HRE confers an increased CV risk. However, there is some indication that an HRE may be related to poor BP control not necessarily detectable under resting conditions. The current gold standard measurement of BP control is 24-hour ambulatory BP monitoring, and this is because it is additive in the prediction of $\mathrm{CV}$ mortality above and beyond clinic BP $[60,61]$. Ambulatory BP is reflective of the BP exposure encountered in daily-life activity and, therefore, more representative of the chronic burden of BP when compared with clinic BP. People generally spend a significant proportion of each day moving (up to 35\% standing and walking) [62], or in an 'ambulatory' state, similar to light intensity exercise. With this in mind, an HRE at a low-to-moderate exercise workload (the intensity of exercise most strongly associated with an increased likelihood of adverse CV outcomes) could be indicative of uncontrolled high BP.

Indeed, pre-hypertensive subjects with an HRE record significantly higher ambulatory $\mathrm{BP}$ values compared to those without an HRE [63]. Raised BP whilst ambulatory, despite normal clinic BP, is indicative of MH (i.e. normal clinic BP but elevated ambulatory or home $\mathrm{BP}$ ), a relatively common BP condition associated with increased CV disease mortality [60, 64]. Studies from our group (and others) have reported a greater incidence of MH in individuals with an HRE (up to $58 \%$ ) $[12,18,19]$. In a recent pilot study of 75 middle-aged untreated subjects with an exaggerated BP response to exercise, we found that light-tomoderate intensity exercise systolic $\mathrm{BP}$ was independently associated with $\mathrm{MH}$ (odds ratio = $1.07,95 \% \mathrm{CI}=1.01-1.12 ; \mathrm{p}=0.015)$, and if the BP response to moderate intensity exercise was $\geq 175 \mathrm{~mm}$ Hg this identified individuals with $\mathrm{MH}$ at $74 \%$ sensitivity and $67 \%$ specificity $(p<0.001)$ [12]. Furthermore, in another analysis, we found that in those individuals with an HRE, MH was associated with increased LV mass and RWT [18]. It is therefore possible that MH may, at least in part, explain the increased CV risk associated with an HRE. Despite this, study samples have only been small and there remains an unmet need for the relationship between an HRE and MH to be assessed in larger studies with more power for generalisability to the wider populace. Until such a study has been completed, an HRE may still serve as a useful warning signal for clinicians to suspect an underlying BP abnormality such as MH.

\section{Treating an HRE}

\section{Pharmacological Interventions}

The effect of $\beta$-blockade on exercise BP has been studied several times and has been shown to significantly reduce exercise BP [65-67]. Indeed, reductions in exercise systolic BP of up to $25 \%$ have been achieved via 4 weeks of active treatment with metoprolol or with combination metoprolol-hydrochlorothiazide [68]. Kokkinos et al. [69] examined a cohort of 2,318 men with hypertension and found that individuals undergoing $\beta$-blocker-based treatments were significantly less likely to attain an exercise BP classified as an HRE during routine 
exercise stress testing, with a $68 \%$ lower risk when compared to other treatment regimens (which included monotherapy or combination therapy with angiotensin-converting enzyme inhibitors, calcium channel blockers and diuretics). However, the duration of exercise testing and intensity of exercise reached by those on $\beta$-blockade treatment was less than those on other treatment regimens [69]. This may be due to a combination of negative chronotropy and impaired exercise tolerance induced with $\beta$-blockade [70], and these effects are likely to reduce maximal achievable systolic BP during exercise testing. Nonetheless, a comprehensive analysis of the long-term intra-arterial haemodynamic effects of different combination therapy and monotherapy antihypertensive compounds (including $\beta$-blockers, $\alpha$-receptor blockers, calcium antagonists, angiotensin-converting enzyme inhibitors, serotonin antagonists and double-acting compounds) was undertaken by Omvik and Lund-Johansen [71]. This work revealed that similar and significant reductions in both resting and exercise systolic and diastolic BP could be achieved over 10 years, irrespective of the drug class (ranging from a 4 to a $20 \%$ systolic BP reduction and from a 4 to a $19 \%$ diastolic BP reduction; $\mathrm{p}<0.05$ for all) [71].

\section{Exercise and Lifestyle Interventions}

Participation in regular physical activity is a well-established therapeutic modality to lower the risk related to both $\mathrm{CV}$ disease and high BP. Indeed, irrespective of pharmacological treatment, physically inactive patients with hypertension have a greater risk of mortality when compared to those who remain physically active [72]. Lifestyle modifications that include regular exercise are widely accepted as important in the prevention and treatment of hypertension $[3,21,73,74]$, and there is clear evidence that exercise training results in clinically significant reductions in resting BP [75-79]. Although there is less information available with respect to the effects of exercise training on exercise BP, training interventions of varying type, frequency, duration and intensity will likely result in clinically meaningful exercise BP reductions in healthy cohorts [73]. However, the beneficial effects of exercise training and lifestyle modification on exercise BP may be more readily evident in populations at a greater risk related to high $\mathrm{BP}$, such as those with essential hypertension, obesity, a sedentary lifestyle or previous cerebrovascular disease events (e.g. transient ischaemic attack) [80-83]. A randomised controlled trial showed that 12 weeks of treadmill-based exercise training could improve both ambulatory and exercise BP measures in individuals with resistant hypertension (defined as uncontrolled BP despite the use of $\geq 3$ antihypertensive medications, including a diuretic) [84]. This is an encouraging study as it demonstrates the efficacy of exercise training when other treatment modes are failing. We also recently completed a randomised study to determine the effect of 1-year lifestyle interventions (exercise and dietary modification) on exercise BP and the development of an HRE in 185 individuals at elevated CV risk due to T2DM [85]. In patients who undertook exercise training, the propensity to develop an HRE at 1 year was less in those with a normal exercise BP at baseline. However, if an HRE was present at baseline, lifestyle intervention was not sufficient to regress individuals to a normal exercise BP response (fig. 3) [85]. This could mean that more intensive longer-duration exercise interventions may be required to elicit reduced exercise BP in the setting of an established HRE.

\section{Identifying the Cause of an HRE}

\section{Metabolic Irregularity}

Hypercholesterolaemia or dyslipidaemias are known contributors to poor CV risk via accelerated atherosclerosis and vascular stiffening [86], but they may also independently 
Fig. 3. The progression or regression of an HRE in patients with T2DM. In participants who did not have an HRE at baseline, 1 year of exercise and lifestyle intervention attenuated the development of an HRE when compared with a control group (29.8 vs. $59.5 \%$ progression to an HRE, $\mathrm{p}=0.006$ ). In participants who did have an HRE at baseline, 1 year of lifestyle intervention did not change the HRE status when compared to a control group $(22.0$ vs. $23.5 \%, p=0.855$ ). Reproduced from Schultz et al. [85] with permission from Wolters Kluwer Health.

Schultz and Sharman: Exercise Hypertension

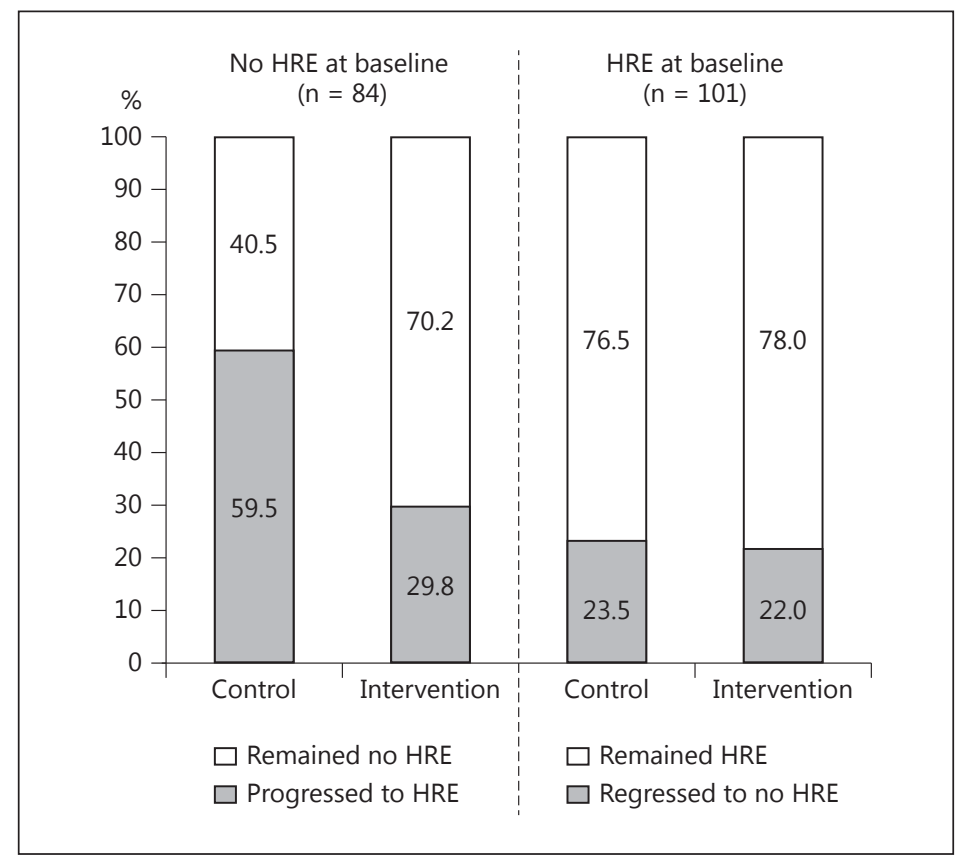

contribute to abnormal elevations in exercise BP. Indeed, a multiple regression analysis of the Framingham cohort data demonstrated an independent relationship between higher total cholesterol-to-high-density cholesterol ratio and submaximal exercise systolic BP [87]. We have also found associations between exercise BP and serum cholesterol [88] as well as triglycerides [89], which is probably attributable to chronic effects of hyperlipidaemia, given that an acute elevation of lipids (with infusion of Intralipid) appears to have no major impact on exercise haemodynamics [90]. Furthermore, a small study of healthy and active men showed a moderate but significant relationship between serum cholesterol concentrations and the change in diastolic BP from rest to exercise $(\mathrm{R}=0.47, \mathrm{p}<0.0001)$ [91]. In this study, insulin resistance was also associated with exercise diastolic BP changes, but there was no correlation between cholesterol or insulin resistance and exercise systolic BP [91]. However, in 275 non-diabetic hypertensive patients, Park et al. [92] showed that insulin resistance assessed by a homeostasis model of insulin resistance $\left(\mathrm{HOMR}_{\mathrm{IR}}\right)$ was significantly raised in those with an HRE, and HOMR $\mathrm{IR}$ predicted the presence of an HRE independently of age, sex, body mass and baseline systolic BP (odds ratio $=2.008, \mathrm{p}<0.001$ ) [92]. Adding to this, insulin resistance has been found to be independently associated with exercise systolic BP in patients with T2DM [93], and insulin sensitivity may also play a role in the regulation of BP during exercise [94]. Taken altogether, a combination of metabolic irregularities including dyslipidaemia and insulin resistance could impair vascular reactivity [95], increase vascular resistance during exercise and contribute to an abnormal increase in BP with exercise.

\section{Systemic Vascular Function}

Appropriate systemic vascular function during exercise is essential for counteracting excessive rises in arterial BP and decreasing LV afterload [4]. Failure of the systemic vasculature to dilate appropriately with exercise may elevate input impedance (ratio of pulsatile pressure to pulsatile flow) and cause a greater rise in systolic BP owing to impaired peripheral vascular runoff. The clinical importance of appropriate vascular function during exercise was examined in the study of Fagard et al. [96], where 143 hypertensive men were followed for 
an equivalent 2,186 patient-years. Systemic vascular resistance measured during exercise was the strongest predictor of future $\mathrm{CV}$ events, irrespective of BP at rest or during exercise [96]. Abnormal endothelium-dependent vasodilatory function could be an underlying contributory mechanism. Indeed, several studies have observed a relationship between impaired peripheral artery reactive hyperaemia and HRE [87, 97-99], but to our knowledge arterial reactivity/function has never been assessed during exercise. Certainly, a decrease in nitric oxide bioavailability under normal resting conditions will perturb muscular artery endothelial function, resulting in a stiffening of the arterial network and an increase in resting systolic BP $[100,101]$. However, during exercise, the effects of nitric oxide on the regulation of the vascular resistance appears less marked than at rest, suggesting that exercise BP responses may be more influenced by other factors or, alternatively, other mechanisms may predominate when nitric oxide is blocked [102-104]. Other research has also identified that systemic markers of vascular inflammation such as C-reactive protein and interleukin- 6 show moderate but significant associations with exercise systolic BP $[105,106]$. Furthermore, the albumin-creatinine ratio (a kidney marker correlated to vascular damage) has been associated with elevations in exercise BP [107], which provides additional evidence of a potential link between an HRE and abnormal vascular function.

\section{Large Artery Stiffness}

With advancing age and disease, the compliance of the large central arteries (namely the aorta and carotid artery) will decline [108]. At rest, aortic pulse wave velocity is strongly associated with CV and all-cause morbidity and mortality and raised BP $[108,109]$. Increased arterial stiffness is also a correlate of an HRE in individuals with essential hypertension [107]. Moreover, aortic pulse wave velocity and central pulse pressure (PP; as a surrogate of large artery stiffness in older people) were recently found to be associated with submaximal exercise systolic BP in men and women of the Framingham offspring cohort [87]. A reduction in aortic compliance could contribute to a decline in the buffering capacity of the vessel when faced with the exercise-induced increase to LV outflow (cardiac output) and lead to an abnormal rise in BP. Moreover, increased distending pressure within the aorta (such as which may be experienced with exercise) is likely to lead to a greater recruitment of collagen fibres and an acute increase in vessel stiffness with exercise, thus also contributing to elevated BP [110]. Exercise has also been shown to significantly stiffen the brachial artery [111]. Properties of the large arteries may be of particular importance to the appropriate regulation of exercise BP in individuals with T2DM. Indeed, whilst there is a high prevalence of an HRE in T2DM patients $[15,16]$, deteriorating glucose tolerance is also associated with increased central and peripheral arterial stiffness [112]. Individuals with insulin resistance and T2DM are also more likely to have greater cardiac output at rest compared to healthy counterparts [113]. If this were to apply in the exercise context, the combination of raised LV output delivered into a stiff proximal aorta will also precipitate an additional rise in exercise BP.

\section{Neural Circulatory Control}

Dynamic exercise requires the initiation of muscular work which is believed to originate in the $\mathrm{CV}$ control centre of the hindbrain, the limbic system and motor cortex regions of the forebrain. As exercise is a voluntary act, the autonomic changes to the CV system are initiated via a 'central command' process (recall from memory) rather than a peripheral sensory input [114]. However, although the central command may be the dominant regulator of the CV system (including changes in BP) during exercise, sympathetic actions of the centre are enhanced by muscle mechanoreceptor and chemoreceptor activity. Peripheral mechanoreceptors provide feedback to the central command relating to the amount and speed of muscular contraction required, whilst chemoreceptors detect and respond to the accumu- 
lation of metabolites deep within the active musculature. Thus, both mechanoreceptors and chemoreceptors may increase the sympathetic outflow from the central command and play an important role in determining the vasoactive state (and thus BP) during exercise. In healthy individuals, exercise-induced sympathetic vasoconstriction is minimised by a protective process known as functional sympatholysis, allowing the maintenance of an appropriate blood flow to active muscles and a 'normotensive' rise in BP ensues with increasing workloads [115]. On the other hand, impairments in functional sympatholysis (i.e. increased sympathetic activity leading to vasoconstriction) may be an underlying cause of an abnormal rise in BP with exercise. Interestingly, studies involving elderly men as well as individuals with hypertension and pre-hypertension (conditions known to be associated with an increased likelihood of an HRE) have shown functional sympatholysis to be impaired with greater activation of muscle chemoreceptors (which result in vasoconstriction) when compared to healthy individuals [115-117]. When combined with enhanced exercise cardiac output, this sympathetic vasoconstriction will likely result in an augmented BP response.

\section{Central Haemodynamics}

Raised brachial BP is a potent predictor of CV and all-cause mortality [118]. However, aortic (central) BP, the pressure to which the organs (heart, brain and kidneys) are directly exposed, predicts CV events independently of brachial BP [119]. At rest, it is well understood that brachial systolic BP is not the same as central systolic BP, as PP becomes amplified with arterial waveform propagation from the large central elastic arteries towards the smaller, more muscular peripheral arteries [120]. Under normal circumstances, this results in central systolic BP being lower than brachial systolic BP and, at rest, central systolic BP may differ considerably between individuals with similar brachial systolic BP (up to $30 \mathrm{~mm} \mathrm{Hg}$ ) [121123]. During exercise, early studies utilising intra-arterial measurement of aortic and radial artery BP indicated that central-to-peripheral PP amplification is raised during exercise when compared to the resting state $[124,125]$. Our own studies, utilising non-invasive estimates of central BP (arterial tonometry), have also revealed significant differences between peripheral and central haemodynamic variables during exercise $[88,126]$. Indeed, PP amplification is increased during moderate intensity exercise in healthy individuals [126] but is blunted (meaning increased central PP relative to brachial PP) during moderate intensity exercise in older individuals and those with hypercholesterolaemia (i.e. those at elevated CV risk) when compared to healthy counterparts [88]. These findings relating to ageing have also been confirmed in a study by Casey et al. [127]. In both these studies, the difference in PP amplification was not discernible at rest, which is relevant because it suggests that the risk related to high BP may be more evident from moderate intensity exercise central BP rather than from brachial BP at rest [13].

Despite the known elevation of central systolic BP with exercise, the augmentation pressure (which is a marker of cardiac load) may reduce with exercise in healthy individuals, possibly owing to decreased peripheral resistance and elevated heart rate $[88,120,125,126]$. On the other hand, in those with established coronary artery disease, the augmentation pressure may increase $[128,129]$. Whilst the haemodynamic mechanisms underlying differential changes in the central haemodynamic load during exercise remain unknown, attempts to reconcile understanding have been focused on frequency-domain analysis and the contribution of wave reflection to augmented exercise BP $[120,128,129]$. Contrary to the findings of these analyses, in an invasive study of exercise aortic BP and flow velocity (in patients who had undergone cardiac catheterisation), we found that the influence of reflected waves on exercise central BP was minimal [130]. Indeed, the elevation in central systolic BP during lightto-moderate intensity exercise appeared to be driven by forward wave propagation as a result of LV contraction forces and related to the 'reservoir' function of the proximal aorta [130]. 
Schultz and Sharman: Exercise Hypertension

\section{Future Directions}

Exercise hypertension appears to have both clinical and prognostic significance, but further studies are required to determine specific values of exercise BP that denote an HRE at specific exercise intensities (i.e. moderate and maximal). This information would better serve to inform clinicians supervising exercise stress testing of normal and diagnostic thresholds indicative of elevated CV risk and/or poor BP control. Much of the work to date on the association of both MH and pre-hypertension with an HRE has been restricted to smallscale non-controlled studies. As such, larger-scale follow-up studies in healthy individuals as well as in patients with an HRE are required to clarify the relationships and potential overlap between these BP conditions. Connecting to this, it may be useful to determine if therapy to 'normalise' an HRE results in improved patient outcomes, or whether the additional risk related to HRE is predominantly owing to uncontrolled BP (delineated by out-of-clinic BP assessment tools) that is inadequately diagnosed and treated. Further resolution of the underlying physiological determinants of high exercise BP is needed, and gaining greater insight into the role of central haemodynamics in the pathogenesis of exercise hypertension will also be a worthwhile area of continued investigation.

\section{Summary and Conclusion}

Exercise hypertension is a common condition that is associated with adverse CV outcomes and, when provoked during exercise testing at a moderate workload, may be indicative of poor BP control. The pathogenic mechanisms underlying an HRE are likely to be related to several CV anomalies, including metabolic (dyslipidaemia, hyperinsulinaemia), neural CV control and vascular (systemic and large artery) dysfunction. Furthermore, exercise BP appears responsive to treatment via both pharmacological and lifestyle (exercise) interventions. However, in order to clarify the true clinical importance and potentially guide the management of the condition, there is a need to determine thresholds of exercise BP above which denote poor prognostic outcome. Altogether, an abnormally high BP recorded during exercise testing may be a clinically useful warning signal to physicians of a BP abnormality warranting further investigation.

\section{References}

1 Australian Government - Medicare Australia: Requested Medicare items processed from January 2011 to December 2011; item 11712: Multi channel ECG monitoring and recording during exercise (accessed February 14, 2012).

- 2 Myers J, Arena R, Franklin B, Pina I, Kraus WE, McInnis K, Balady GJ: Recommendations for clinical exercise laboratories: a scientific statement from the American Heart Association. Circulation 2009;119:3144-3161.

3 Sharman JE, Stowasser M: Australian association for exercise and sports science position statement on exercise and hypertension. J Sci Med Sport 2009;12:252-257.

4 Munir S, Jiang B, Guilcher A, Brett S, Redwood S, Marber M, Chowienczyk P: Exercise reduces arterial pressure augmentation through vasodilation of muscular arteries in humans. Am J Physiol Heart Circ Physiol 2008; 294:H1645-H1650.

5 Klabunde R: Cardiovascular Physiology Concepts. Philadelphia, Lippincott Williams \& Wilkins, 2005.

- 6 Holland DJ, Sacre JW, McFarlane SJ, Coombes JS, Sharman JE: Pulse wave analysis is a reproducible technique for measuring central blood pressure during hemodynamic perturbations induced by exercise. Am J Hypertens 2008;21:1100-1106.

7 Daida H, Allison TG, Squires RW, Miller TD, Gau GT: Peak exercise blood pressure stratified by age and gender in apparently healthy subjects. Mayo Clin Proc 1996;71:445-452.

8 Lauer MS, Pashkow FJ, Harvey SA, Marwick TH, Thomas JD: Angiographic and prognostic implications of an exaggerated exercise systolic blood pressure response and rest systolic blood pressure in adults undergoing evaluation for suspected coronary artery disease. J Am Coll Cardiol 1995;26:1630-1636. 
Schultz and Sharman: Exercise Hypertension

- 9 Allison TG, Cordeiro MA, Miller TD, Daida H, Squires RW, Gau GT: Prognostic significance of exercise-induced systemic hypertension in healthy subjects. Am J Cardiol 1999;83:371-375.

-10 Mottram PM, Haluska B, Yuda S, Leano R, Marwick TH: Patients with a hypertensive response to exercise have impaired systolic function without diastolic dysfunction or left ventricular hypertrophy. J Am Coll Cardiol 2004;43:848-853.

-11 Manolio TA, Burke GL, Savage PJ, Sidney S, Gardin JM, Oberman A: Exercise blood pressure response and 5-year risk of elevated blood pressure in a cohort of young adults: the CARDIA study. Am J Hypertens 1994;7: 234-241.

12 Schultz MG, Hare JL, Marwick TH, Stowasser M, Sharman JE: Masked hypertension is 'unmasked' by lowintensity exercise blood pressure. Blood Press 2011;20:284-289.

13 Sharman J: New insights into cardiovascular risk from the exercise central waveform. Artery Res 2008;2: 132-137.

14 Scott JA, Coombes JS, Prins JB, Leano RL, Marwick TH, Sharman JE: Patients with type 2 diabetes have exaggerated brachial and central exercise blood pressure: relation to left ventricular relative wall thickness. Am J Hypertens 2008;21:715-721.

15 Kramer CK, Leitao CB, Canani LH, Ricardo ED, Pinto LC, Gross JL: Blood pressure responses to exercise in type II diabetes mellitus patients with masked hypertension. J Hum Hypertens 2009;23:620-622.

16 Le VV, Mitiku T, Sungar G, Myers J, Froelicher V: The blood pressure response to dynamic exercise testing: a systematic review. Prog Cardiovasc Dis 2008;51:135-160.

17 Blake GA, Levin SR, Koyal SN: Exercise-induced hypertension in normotensive patients with NIDDM. Diabetes Care 1990;13:799-801.

18 Sharman JE, Hare JL, Thomas S, Davies JE, Leano R, Jenkins C, Marwick TH: Association of masked hypertension and left ventricular remodeling with the hypertensive response to exercise. Am J Hypertens 2011;24: 898-903.

19 Kayrak M, Bacaksiz A, Vatankulu MA, Ayhan SS, Kaya Z, Ari H, Sonmez O, Gok H: Exaggerated blood pressure response to exercise - a new portent of masked hypertension. Clin Exp Hypertens 2010;32:560-568.

-20 Kokkinos PF, Andreas PE, Coutoulakis E, Colleran JA, Narayan P, Dotson CO, Choucair W, Farmer C, Fernhall B: Determinants of exercise blood pressure response in normotensive and hypertensive women: role of cardiorespiratory fitness. J Cardiopulm Rehabil 2002;22:178-183.

-21 Chobanian AV, Bakris GL, Black HR, Cushman WC, Green LA, Izzo JL Jr, Jones DW, Materson BJ, Oparil S, Wright JT Jr, Roccella EJ: Seventh report of the Joint National Committee on Prevention, Detection, Evaluation, and Treatment of High Blood Pressure. Hypertension 2003;42:1206-1252.

-22 Mundal R, Kjeldsen SE, Sandvik L, Erikssen G, Thaulow E, Erikssen J: Predictors of 7-year changes in exercise blood pressure: effects of smoking, physical fitness and pulmonary function. J Hypertens 1997; 15:245-249.

-23 Mundal R, Kjeldsen SE, Sandvik L, Erikssen G, Thaulow E, Erikssen J: Seasonal covariation in physical fitness and blood pressure at rest and during exercise in healthy middle-aged men. Blood Press 1997;6:269-273.

-24 Kristal-Boneh E, Froom P, Harari G, Silber H, Ribak J: Exercise blood pressure changes between seasons. Blood Press Monit 1997;2:223-227.

25 Sharabi Y, Ben-Cnaan R, Hanin A, Martonovitch G, Grossman E: The significance of hypertensive response to exercise as a predictor of hypertension and cardiovascular disease. J Hum Hypertens 2001;15:353-356.

-26 Farah R, Shurtz-Swirski R, Nicola M: High blood pressure response to stress ergometry could predict future hypertension. Eur J Intern Med 2009;20:366-368.

-27 Matthews CE, Pate RR, Jackson KL, Ward DS, Macera CA, Kohl HW, Blair SN: Exaggerated blood pressure response to dynamic exercise and risk of future hypertension. J Clin Epidemiol 1998;51:29-35.

-28 Miyai N, Arita M, Miyashita K, Morioka I, Shiraishi T, Nishio I: Blood pressure response to heart rate during exercise test and risk of future hypertension. Hypertension 2002;39:761-766.

29 Miyai N, Arita M, Morioka I, Miyashita K, Nishio I, Takeda S: Exercise BP response in subjects with high-normal BP: exaggerated blood pressure response to exercise and risk of future hypertension in subjects with highnormal blood pressure. J Am Coll Cardiol 2000;36:1626-1631.

-30 Tsumura K, Hayashi T, Hamada C, Endo G, Fujii S, Okada K: Blood pressure response after two-step exercise as a powerful predictor of hypertension: the Osaka Health Survey. J Hypertens 2002;20:1507-1512.

-31 Singh JP, Larson MG, Manolio TA, O’Donnell CJ, Lauer M, Evans JC, Levy D: Blood pressure response during treadmill testing as a risk factor for new-onset hypertension. The Framingham heart study. Circulation 1999; 99:1831-1836.

-32 Nakashima M, Miura K, Kido T, Saeki K, Tamura N, Matsui S, Morikawa Y, Nishijo M, Nakanishi Y, Nakagawa H: Exercise blood pressure in young adults as a predictor of future blood pressure: a 12-year follow-up of medical school graduates. J Hum Hypertens 2004;18:815-821.

-33 Franklin SS, Pio JR, Wong ND, Larson MG, Leip EP, Vasan RS, Levy D: Predictors of new-onset diastolic and systolic hypertension: the Framingham Heart Study. Circulation 2005;111:1121-1127.

-34 Fagard R, Staessen J, Amery A: Exercise blood pressure and target organ damage in essential hypertension. J Hum Hypertens 1991;5:69-75.

35 Georgiades A, Lemne C, de Faire U, Lindvall K, Fredrikson M: Stress-induced laboratory blood pressure in relation to ambulatory blood pressure and left ventricular mass among borderline hypertensive and normotensive individuals. Hypertension 1996;28:641-646. 
Schultz and Sharman: Exercise Hypertension

-36 Nathwani D, Reeves RA, Marquez-Julio A, Leenen FH: Left ventricular hypertrophy in mild hypertension: correlation with exercise blood pressure. Am Heart J 1985;109:386-387.

-37 Gottdiener JS, Brown J, Zoltick J, Fletcher RD: Left ventricular hypertrophy in men with normal blood pressure: relation to exaggerated blood pressure response to exercise. Ann Intern Med 1990;112:161-166.

-38 Ren JF, Hakki AH, Kotler MN, Iskandrian AS: Exercise systolic blood pressure: a powerful determinant of increased left ventricular mass in patients with hypertension. J Am Coll Cardiol 1985;5:1224-1231.

-39 Papademetriou V, Notargiacomo A, Sethi E, Costello R, Fletcher R, Freis ED: Exercise blood pressure response and left ventricular hypertrophy. Am J Hypertens 1989;2:114-116.

$>40$ Pierson LM, Bacon SL, Sherwood A, Hinderliter AL, Babyak M, Gullette EC, Waugh R, Blumenthal JA: Relationship between exercise systolic blood pressure and left ventricular geometry in overweight, mildly hypertensive patients. J Hypertens 2004;22:399-405.

41 Sung J, Ouyang P, Silber HA, Bacher AC, Turner KL, DeRegis JR, Hees PS, Shapiro EP, Stewart KJ: Exercise blood pressure response is related to left ventricular mass. J Hum Hypertens 2003;17:333-338.

$\checkmark 42$ Lauer MS, Levy D, Anderson KM, Plehn JF: Is there a relationship between exercise systolic blood pressure response and left ventricular mass? The Framingham Heart Study. Ann Intern Med 1992;116:203-210.

43 Weiner MM, Reich DL, Lin HM, Krol M, Fischer GW: Increased left ventricular myocardial mass is associated with arrhythmias after cardiac surgery. J Cardiothorac Vasc Anesth 2013;27:292-297.

44 Okin PM, Bang CN, Wachtell K, Hille DA, Kjeldsen SE, Dahlof B, Devereux RB: Relationship of sudden cardiac death to new-onset atrial fibrillation in hypertensive patients with left ventricular hypertrophy. Circ Arrhythm Electrophysiol 2013;6:243-251.

45 Filipovsky J, Ducimetiere P, Safar ME: Prognostic significance of exercise blood pressure and heart rate in middle-aged men. Hypertension 1992;20:333-339.

46 Kohl HW 3rd, Nichaman MZ, Frankowski RF, Blair SN: Maximal exercise hemodynamics and risk of mortality in apparently healthy men and women. Med Sci Sports Exerc 1996;28:601-609.

47 Mundal R, Kjeldsen SE, Sandvik L, Erikssen G, Thaulow E, Erikssen J: Exercise blood pressure predicts mortality from myocardial infarction. Hypertension 1996;27:324-329.

-48 Kjeldsen SE, Mundal R, Sandvik L, Erikssen G, Thaulow E, Erikssen J: Supine and exercise systolic blood pressure predict cardiovascular death in middle-aged men. J Hypertens 2001;19:1343-1348.

49 Kurl S, Laukkanen JA, Rauramaa R, Lakka TA, Sivenius J, Salonen JT: Systolic blood pressure response to exercise stress test and risk of stroke. Stroke 2001;32:2036-2041.

50 Weiss SA, Blumenthal RS, Sharrett AR, Redberg RF, Mora S: Exercise blood pressure and future cardiovascular death in asymptomatic individuals. Circulation 2010;121:2109-2116.

51 Laukkanen JA, Kurl S, Rauramaa R, Lakka TA, Venalainen JM, Salonen JT: Systolic blood pressure response to exercise testing is related to the risk of acute myocardial infarction in middle-aged men. Eur J Cardiovasc Prev Rehabil 2006;13:421-428.

52 Skretteberg PT, Grundvold I, Kjeldsen SE, Engeseth K, Liestol K, Erikssen G, Erikssen J, Gjesdal K, Bodegard J: Seven-year increase in exercise systolic blood pressure at moderate workload predicts long-term risk of coronary heart disease and mortality in healthy middle-aged men. Hypertension 2013;61:1134-1140.

53 Lewis GD, Gona P, Larson MG, Plehn JF, Benjamin EJ, O’Donnell CJ, Levy D, Vasan RS, Wang TJ: Exercise blood pressure and the risk of incident cardiovascular disease (from the Framingham Heart Study). Am J Cardiol 2008;101:1614-1620.

54 Schultz MG, Otahal P, Cleland VJ, Blizzard L, Marwick TH, Sharman JE: Exercise-induced hypertension, cardiovascular events, and mortality in patients undergoing exercise stress testing: a systematic review and metaanalysis. Am J Hypertens 2013;26:357-366.

-55 Fagard R, Staessen J, Thijs L, Amery A: Prognostic significance of exercise versus resting blood pressure in hypertensive men. Hypertension 1991;17:574-578.

56 Campbell L, Marwick TH, Pashkow FJ, Snader CE, Lauer MS: Usefulness of an exaggerated systolic blood pressure response to exercise in predicting myocardial perfusion defects in known or suspected coronary artery disease. Am J Cardiol 1999;84:1304-1310.

57 Gupta MP, Polena S, Coplan N, Panagopoulos G, Dhingra C, Myers J, Froelicher V: Prognostic significance of systolic blood pressure increases in men during exercise stress testing. Am J Cardiol 2007;100:1609-1613.

58 Habibzadeh MR, Farzaneh-Far R, Sarna P, Na B, Schiller NB, Whooley MA: Association of blood pressure and heart rate response during exercise with cardiovascular events in the heart and soul study. J Hypertens 2010; 28:2236-2242.

59 Hamalainen H, Luurila OJ, Kallio V, Hakkila J, Arstila M, Vuori I, Knuts LR: Prognostic value of an exercise test one year after myocardial infarction. Ann Med 1989;21:447-453.

60 Mancia G, Facchetti R, Bombelli M, Grassi G, Sega R: Long-term risk of mortality associated with selective and combined elevation in office, home, and ambulatory blood pressure. Hypertension 2006;47:846-853.

61 Mancia G, Fagard R, Narkiewicz K, et al: 2013 ESH/ESC guidelines for the management of arterial hypertension: the Task Force for the Management of Arterial Hypertension of the European Society of Hypertension (ESH) and of the European Society of Cardiology (ESC). Eur Heart J 2013;34:2159-2219.

62 Cavelaars M, Tulen JH, van Bemmel JH, Mulder PG, van den Meiracker AH: Haemodynamic responses to physical activity and body posture during everyday life. J Hypertens 2004;22:89-96. 
Schultz and Sharman: Exercise Hypertension

63 Lima EG, Spritzer N, Herkenhoff FL, Bermudes A, Vasquez EC: Noninvasive ambulatory 24-h blood pressure in patients with high normal blood pressure and exaggerated systolic pressure response to exercise. Hypertension 1995;26:1121-1124.

64 Mancia G, Bombelli M, Facchetti R, Madotto F, Quarti-Trevano F, Friz HP, Grassi G, Sega R: Long-term risk of sustained hypertension in white-coat or masked hypertension. Hypertension 2009;54:226-232.

65 White WB, Schulman P, McCabe EJ, Hager WD: Effects of chronic cetamolol therapy on resting, ambulatory, and exercise blood pressure and heart rate. Clin Pharmacol Ther 1986;39:664-668.

66 Haasis R, Bethge H: Exercise blood pressure and heart rate reduction 24 and $3 \mathrm{~h}$ after drug intake in hypertensive patients following 4 weeks of treatment with bisoprolol and metoprolol: a randomized multicentre double-blind study (BISOMET). Eur Heart J 1987;8(suppl M):103-113.

-67 Franz IW, Behr U, Ketelhut R: Resting and exercise blood pressure with atenolol, enalapril and a low-dose combination. J Hypertens Suppl 1987;5:S37-S41.

68 Lorimer AR, Barbour MB, Lawrie TD: An evaluation of the effect on resting and exercise blood pressure of some first line treatments in hypertension. Ann Clin Res 1983;15:30-34.

-69 Kokkinos P, Chrysohoou C, Panagiotakos D, Narayan P, Greenberg M, Singh S: Beta-blockade mitigates exercise blood pressure in hypertensive male patients. J Am Coll Cardiol 2006;47:794-798.

70 Gordon NF, Duncan JJ: Effect of beta-blockers on exercise physiology: implications for exercise training. Med Sci Sports Exerc 1991;23:668-676.

-71 Omvik P, Lund-Johansen P: Long-term hemodynamic effects at rest and during exercise of newer antihypertensive agents and salt restriction in essential hypertension: review of epanolol, doxazosin, amlodipine, felodipine, diltiazem, lisinopril, dilevalol, carvedilol, and ketanserin. Cardiovasc Drugs Ther 1993;7:193-206.

$\checkmark 72$ Brown RE, Riddell MC, Macpherson AK, Canning KL, Kuk JL: The joint association of physical activity, bloodpressure control, and pharmacologic treatment of hypertension for all-cause mortality risk. Am J Hypertens 2013;26:1005-1010.

73 Pescatello LS, Franklin BA, Fagard R, Farquhar WB, Kelley GA, Ray CA: American college of sports medicine position stand. Exercise and hypertension. Med Sci Sports Exerc 2004;36:533-553.

74 Mancia G, De Backer G, Dominiczak A, et al: 2007 Guidelines for the management of arterial hypertension: The Task Force for the Management of Arterial Hypertension of the European Society of Hypertension (ESH) and of the European Society of Cardiology (ESC). Eur Heart J 2007;28:1462-1536.

75 Cornelissen VA, Buys R, Smart NA: Endurance exercise beneficially affects ambulatory blood pressure: a systematic review and meta-analysis. J Hypertens 2013;31:639-648.

76 Halbert JA, Silagy CA, Finucane P, Withers RT, Hamdorf PA, Andrews GR: The effectiveness of exercise training in lowering blood pressure: a meta-analysis of randomised controlled trials of 4 weeks or longer. J Hum Hypertens 1997;11:641-649.

77 Whelton SP, Chin A, Xin X, He J: Effect of aerobic exercise on blood pressure: a meta-analysis of randomized, controlled trials. Ann Intern Med 2002;136:493-503.

-78 Kokkinos PF, Narayan P, Colleran JA, Pittaras A, Notargiacomo A, Reda D, Papademetriou V: Effects of regular exercise on blood pressure and left ventricular hypertrophy in African-American men with severe hypertension. N Engl J Med 1995;333:1462-1467.

-79 Cornelissen VA, Smart NA: Exercise training for blood pressure: a systematic review and meta-analysis. J Am Heart Assoc 2013;2:e004473.

-80 Marceau M, Kouame N, Lacourciere Y, Cleroux J: Effects of different training intensities on 24-h blood pressure in hypertensive subjects. Circulation 1993;88:2803-2811.

-81 Cox KL, Puddey IB, Morton AR, Burke V, Beilin LJ, McAleer M: Exercise and weight control in sedentary overweight men: effects on clinic and ambulatory blood pressure. J Hypertens 1996;14:779-790.

82 Van Hoof R, Hespel P, Fagard R, Lijnen P, Staessen J, Amery A: Effect of endurance training on blood pressure at rest, during exercise and during $24 \mathrm{~h}$ in sedentary men. Am J Cardiol 1989;63:945-949.

83 Faulkner J, McGonigal G, Woolley B, Stoner L, Wong L, Lambrick D: The effect of a short-term exercise programme on haemodynamic adaptability; a randomised controlled trial with newly diagnosed transient ischaemic attack patients. J Hum Hypertens 2013;27:736-743.

-84 Dimeo F, Pagonas N, Seibert F, Arndt R, Zidek W, Westhoff TH: Aerobic exercise reduces blood pressure in resistant hypertension. Hypertension 2012;60:653-658.

-85 Schultz MG, Hordern MD, Leano R, Coombes JS, Marwick TH, Sharman JE: Lifestyle change diminishes a hypertensive response to exercise in type 2 diabetes. Med Sci Sports Exerc 2011;43:764-769.

-86 Wilkinson IB, Prasad K, Hall IR, Thomas A, MacCallum H, Webb DJ, Frenneaux MP, Cockcroft JR: Increased central pulse pressure and augmentation index in subjects with hypercholesterolemia. J Am Coll Cardiol 2002; 39:1005-1011.

87 Thanassoulis G, Lyass A, Benjamin EJ, Larson MG, Vita JA, Levy D, Hamburg NM, Widlansky ME, O’Donnell CJ, Mitchell GF, Vasan RS: Relations of exercise blood pressure response to cardiovascular risk factors and vascular function in the Framingham Heart Study. Circulation 2012;125:2836-2843.

88 Sharman JE, McEniery CM, Dhakam ZR, Coombes JS, Wilkinson IB, Cockcroft JR: Pulse pressure amplification during exercise is significantly reduced with age and hypercholesterolemia. J Hypertens 2007;25:1249-1254.

89 Sharman JE, Brown J, Holland DJ, Macdonald G, Kostner K, Marwick TH: Influence of altered blood rheology on ventricular-vascular response to exercise. Hypertension 2009;54:1092-1098. 
Schultz and Sharman: Exercise Hypertension

90 Sharman JE, Holland DJ, Leano R, Kostner KM: Acute elevation of lipids does not alter exercise hemodynamics in healthy men: a randomized controlled study. Atherosclerosis 2013;226:234-237.

91 Brett SE, Ritter JM, Chowienczyk PJ: Diastolic blood pressure changes during exercise positively correlate with serum cholesterol and insulin resistance. Circulation 2000;101:611-615.

92 Park S, Shim J, Kim JB, Ko YG, Choi D, Ha JW, Rim SJ, Jang Y, Chung N: Insulin resistance is associated with hypertensive response to exercise in non-diabetic hypertensive patients. Diabetes Res Clin Pract 2006;73: 65-69.

93 Kumagai S, Kai Y, Hanada H, Uezono K, Sasaki H: Relationships of the systolic blood pressure response during exercise with insulin resistance, obesity, and endurance fitness in men with type 2 diabetes mellitus. Metabolism 2002;51:1247-1252.

94 Fossum E, Hoieggen A, Moan A, Rostrup M, Kjeldsen SE: Insulin sensitivity is related to physical fitness and exercise blood pressure to structural vascular properties in young men. Hypertension 1999;33:781-786.

95 Steinberg HO, Chaker H, Leaming R, Johnson A, Brechtel G, Baron AD: Obesity/insulin resistance is associated with endothelial dysfunction. Implications for the syndrome of insulin resistance. J Clin Invest 1996;97:26012610.

96 Fagard RH, Pardaens K, Staessen JA, Thijs L: Prognostic value of invasive hemodynamic measurements at rest and during exercise in hypertensive men. Hypertension 1996;28:31-36.

97 Stewart KJ, Sung J, Silber HA, Fleg JL, Kelemen MD, Turner KL, Bacher AC, Dobrosielski DA, DeRegis JR, Shapiro EP, Ouyang P: Exaggerated exercise blood pressure is related to impaired endothelial vasodilator function. Am J Hypertens 2004;17:314-320.

98 Tzemos N, Lim PO, MacDonald TM: Exercise blood pressure and endothelial dysfunction in hypertension. Int J Clin Pract 2009;63:202-206.

99 Chang HJ, Chung J, Choi SY, Yoon MH, Hwang GS, Shin JH, Tahk SJ, Choi BI: Endothelial dysfunction in patients with exaggerated blood pressure response during treadmill test. Clin Cardiol 2004;27:421-425.

100 McEniery CM, Wallace S, Mackenzie IS, McDonnell B, Yasmin, Newby DE, Cockcroft JR, Wilkinson IB: Endothelial function is associated with pulse pressure, pulse wave velocity, and augmentation index in healthy humans. Hypertension 2006;48:602-608.

101 Sugawara J, Komine H, Hayashi K, Yoshizawa M, Yokoi T, Otsuki T, Shimojo N, Miyauchi T, Maeda S, Tanaka H: Effect of systemic nitric oxide synthase inhibition on arterial stiffness in humans. Hypertens Res 2007;30: 411-415.

102 Brett SE, Cockcroft JR, Mant TG, Ritter JM, Chowienczyk PJ: Haemodynamic effects of inhibition of nitric oxide synthase and of l-arginine at rest and during exercise. J Hypertens 1998;16:429-435.

103 Sharman JE, McEniery CM, Campbell R, Pusalkar P, Wilkinson IB, Coombes JS, Cockcroft JR: Nitric oxide does not significantly contribute to changes in pulse pressure amplification during light aerobic exercise. Hypertension 2008;51:856-861.

104 Gilligan DM, Panza JA, Kilcoyne CM, Waclawiw MA, Casino PR, Quyyumi AA: Contribution of endotheliumderived nitric oxide to exercise-induced vasodilation. Circulation 1994;90:2853-2858.

105 Hamer M, Steptoe A: Vascular inflammation and blood pressure response to acute exercise. Eur J Appl Physiol 2012;112:2375-2379.

106 Jae SY, Fernhall B, Lee M, Heffernan KS, Lee MK, Choi YH, Hong KP, Park WH: Exaggerated blood pressure response to exercise is associated with inflammatory markers. J Cardiopulm Rehabil 2006;26:145-149.

107 Tsioufis C, Dimitriadis K, Thomopoulos C, Tsiachris D, Selima M, Stefanadi E, Tousoulis D, Kallikazaros I, Stefanadis C: Exercise blood pressure response, albuminuria, and arterial stiffness in hypertension. Am J Med 2008; 121:894-902.

108 Laurent S, Cockcroft J, Van Bortel L, Boutouyrie P, Giannattasio C, Hayoz D, Pannier B, Vlachopoulos C, Wilkinson I, Struijker-Boudier H: Expert consensus document on arterial stiffness: methodological issues and clinical applications. Eur Heart J 2006;27:2588-2605.

109 Vlachopoulos C, Aznaouridis K, Stefanadis C: Prediction of cardiovascular events and all-cause mortality with arterial stiffness: a systematic review and meta-analysis. J Am Coll Cardiol 2010;55:1318-1327.

110 Armentano RL, Levenson J, Barra JG, Fischer EI, Breitbart GJ, Pichel RH, Simon A: Assessment of elastin and collagen contribution to aortic elasticity in conscious dogs. Am J Physiol 1991;260:H1870-H1877.

111 Naka KK, Tweddel AC, Parthimos D, Henderson A, Goodfellow J, Frenneaux MP: Arterial distensibility: acute changes following dynamic exercise in normal subjects. Am J Physiol Heart Circ Physiol 2003;284:H970H978.

112 Schram MT, Henry RM, van Dijk RA, Kostense PJ, Dekker JM, Nijpels G, Heine RJ, Bouter LM, Westerhof N, Stehouwer CD: Increased central artery stiffness in impaired glucose metabolism and type 2 diabetes: the Hoorn Study. Hypertension 2004;43:176-181.

113 Velagaleti RS, Gona P, Chuang ML, Salton CJ, Fox CS, Blease SJ, Yeon SB, Manning WJ, O’Donnell CJ: Relations of insulin resistance and glycemic abnormalities to cardiovascular magnetic resonance measures of cardiac structure and function: the Framingham Heart Study. Circ Cardiovasc Imaging 2010;3:257-263.

114 Gandevia SC, Killian K, McKenzie DK, Crawford M, Allen GM, Gorman RB, Hales JP: Respiratory sensations, cardiovascular control, kinaesthesia and transcranial stimulation during paralysis in humans. J Physiol 1993; 470:85-107.

115 Saltin B, Mortensen SP: Inefficient functional sympatholysis is an overlooked cause of malperfusion in contracting skeletal muscle. J Physiol 2012;590:6269-6275. 
Schultz and Sharman: Exercise Hypertension

116 Vongpatanasin W, Wang Z, Arbique D, Arbique G, Adams-Huet B, Mitchell JH, Victor RG, Thomas GD: Functional sympatholysis is impaired in hypertensive humans. J Physiol 2011;589:1209-1220.

117 Choi HM, Stebbins CL, Lee OT, Nho H, Lee JH, Chun JM, Kim KA, Kim JK: Augmentation of the exercise pressor reflex in prehypertension: roles of the muscle metaboreflex and mechanoreflex. Appl Physiol Nutr Metab 2013;38:209-215.

118 Lewington S, Clarke R, Qizilbash N, Peto R, Collins R: Age-specific relevance of usual blood pressure to vascular mortality: a meta-analysis of individual data for one million adults in 61 prospective studies. Lancet 2002;360: 1903-1913.

119 Vlachopoulos C, Aznaouridis K, O’Rourke MF, Safar ME, Baou K, Stefanadis C: Prediction of cardiovascular events and all-cause mortality with central haemodynamics: a systematic review and meta-analysis. Eur Heart J 2010;31:1865-1871.

120 Nichols WW, O’Rourke MF: McDonald's Blood Flow in Arteries: Theoretical, Experimental and Clinical Principles. London, Hodder Arnold, 2005.

121 Schultz MG, Gilroy D, Wright L, Bishop WL, Abhayaratna WP, Stowasser M, Sharman JE: Out-of-office and central blood pressure for risk stratification: a cross-sectional study in patients treated for hypertension. Eur J Clin Invest 2012;42:393-401.

122 Sharman J, Stowasser M, Fassett R, Marwick T, Franklin S: Central blood pressure measurement may improve risk stratification. J Hum Hypertens 2008;22:838-844.

123 McEniery CM, Yasmin, McDonnell B, Munnery M, Wallace SM, Rowe CV, Cockcroft JR, Wilkinson IB: Central pressure: variability and impact of cardiovascular risk factors: the Anglo-Cardiff Collaborative Trial II. Hypertension 2008;51:1476-1482.

124 Kroeker EJ, Wood EH: Comparison of simultaneously recorded central and peripheral arterial pressure pulses during rest, exercise and tilted position in man. Circ Res 1955;3:623-632.

125 Rowell LB, Brengelmann GL, Blackmon JR, Bruce RA, Murray JA: Disparities between aortic and peripheral pulse pressures induced by upright exercise and vasomotor changes in man. Circulation 1968;37:954-964.

126 Sharman JE, McEniery CM, Campbell RI, Coombes JS, Wilkinson IB, Cockcroft JR: The effect of exercise on large artery haemodynamics in healthy young men. Eur J Clin Invest 2005;35:738-744.

127 Casey DP, Nichols WW, Braith RW: Impact of aging on central pressure wave reflection characteristics during exercise. Am J Hypertens 2008;21:419-424.

128 Murgo JP, Westerhof N, Giolma JP, Altobelli SA: Effects of exercise on aortic input impedance and pressure wave forms in normal humans. Circ Res 1981;48:334-343.

129 Laskey WK, Kussmaul WG, Martin JL, Kleaveland JP, Hirshfeld JW Jr, Shroff S: Characteristics of vascular hydraulic load in patients with heart failure. Circulation 1985;72:61-71.

130 Schultz MG, Davies JE, Roberts-Thomson P, Black JA, Hughes AD, Sharman JE: Exercise central (aortic) blood pressure is predominantly driven by forward traveling waves, not wave reflection. Hypertension 2013;62: 175-182. 